Case Report

\title{
Subdural empyema as a rare complication of sinonasal infection: a case report and review of literature
}

\author{
Fatih Yakar $^{1 *}$, Ihsan Dogan', Onur Ozgural ${ }^{1}$, Umit Eroglu', Suha Beton², Agahan Unlu1
}

\author{
${ }^{1}$ Department of Neurosurgery, Ankara University School of Medicine, Ankara, Turkey \\ ${ }^{2}$ Department of Otorhinolaryngology-Head and Neck Surgery, Ankara University School of Medicine, Ankara, \\ Turkey
}

Received: 02 August 2017

Accepted: 27 August 2017

\author{
*Correspondence: \\ Dr. Fatih Yakar, \\ E-mail: yakarneurosurgery@gmail.com
}

Copyright: ( ) the author(s), publisher and licensee Medip Academy. This is an open-access article distributed under the terms of the Creative Commons Attribution Non-Commercial License, which permits unrestricted non-commercial use, distribution, and reproduction in any medium, provided the original work is properly cited.

\begin{abstract}
Subdural empyema is a rare complication that causes high morbidity and mortality following sinusitis. Cranial complications should be considered in patients who develop neurological symptoms. These patients need surgery that should be performed by neurological and ear-nose-throat surgeons working together. A 14-year-old girl developed aphasia and hemiparesis from retrograde thrombophlebitis following sinusitis and we planned a two-stage surgery for the patient. In the first step, we drained the empyema by a craniotomy and functional endoscopic sinus surgery. In the second step, we drained a mature abscess. The purpose of this paper is to review the surgical and clinical management of intracranial complications from sinonasal infections.
\end{abstract}

Keywords: Complication, Sinonasal infection, Subdural empyema

\section{INTRODUCTION}

Intracranial complications from sinusitis are uncommon, but result in high morbidity and mortality. ${ }^{1}$ Spreading to the cranial region occurs by direct extension of the venous, lymphatic and perineural pathways. Sinusitis induced brain abscesses often develop in the frontal lobes and the most frequently reported complication is subdural empyema., ${ }^{2,3}$ Cranial complications require surgical management and sinus surgery should be added to the treatment.

\section{CASE REPORT}

A 14-year-old girl was admitted to our clinic with confusion, aphasia and right hemiparesis that had been ongoing for two days. Second-generation oral cephalosporin was given to the patient, who had been diagnosed with sinusitis five days earlier. She had a fever during the physical examination. During the neurologic examination, she had a tendency for sleep, aphasia and right hemiparesis (3/5 MRC- Muscle Strength Grading Scale). Magnetic resonance imaging (MRI) (Figure 1a and $1 \mathrm{~b}$ and $2 \mathrm{c}$ and $2 \mathrm{~d}$ ) and computed tomography (CT) (Figure $2 \mathrm{a}$ and $2 \mathrm{~b}$ ) were performed and we detected a 9$\mathrm{mm}$ thick subdural empyema that caused a 5-mm shift from the midline to the right.

The patient was scheduled for emergency surgery. A 6$\mathrm{cm}$ long skin incision from $1 \mathrm{~cm}$ above the superior temporal line to $1 \mathrm{~cm}$ behind the coronal suture was performed. The temporal muscle was dissected $2 \mathrm{~cm}$ inferiorly and temporoparietal craniotomy behind the coronal suture was performed. The subdural abscess was drained rapidly, following a linear dural incision with high-pressure (Figure 3a), brain relaxation and pulsation were observed and culture samples were taken. Functional endoscopic sinus surgery, including frontal sinusotomy, was performed by ear-nose-throat (ENT) surgeons as the first step of surgery in the same session with subdural empyema decompression (Figure 3e-h). In the postoperative second hour, a partial seizure occurred 
on the right half of the face that lasted 20 seconds. Seizures were controlled with anti-epileptic drug treatment.

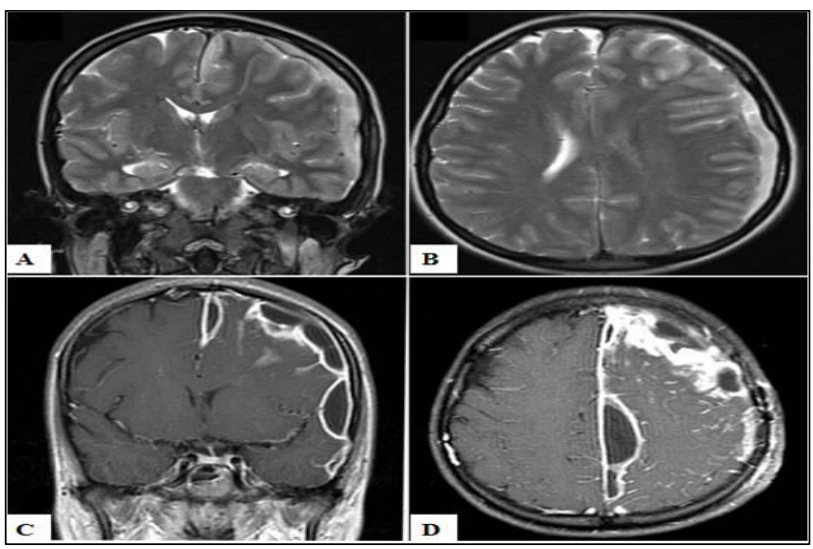

Figure 1a, 1b, 1c and 1d: Coronal section (a) and axial MRI sections (b) of frontotemporoparietal subdural empyema before the first surgery. Coronal section (c) and axial MRI sections (d) of frontotemporoparietal subdural empyema revealing cystic enlargement, abscess' wall thickening and contrast enhancement of previous lesions 2 months after the first surgery.

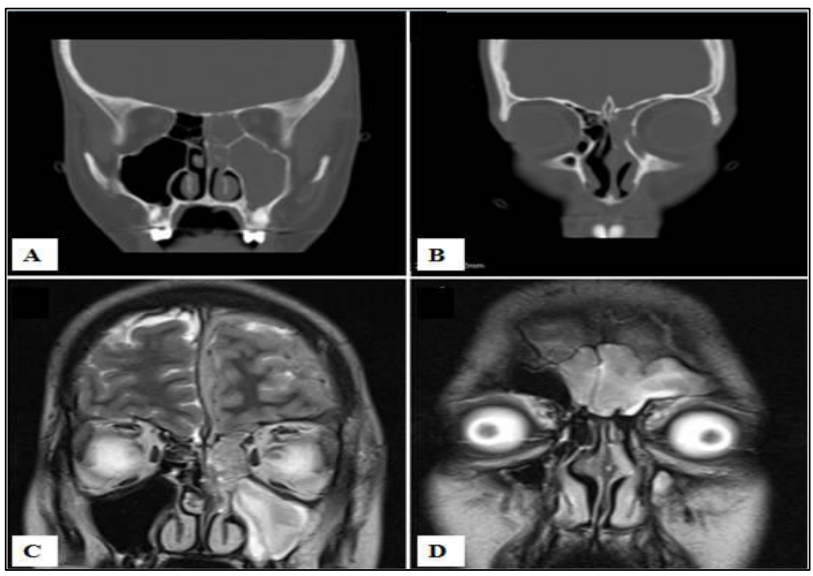

Figure 2a, 2b, 2c and 2d: Coronal sections of paranasal Ct (a,b) and cranial MRI (c,d) show inflammatory and infective views conformable with frontal and maxillary sinusitis in the left paranasal sinuses without bone destruction.

Any microorganisms present were isolated in the culture samples. Aphasia and hemiparesis decreased gradually in the first month postsurgery. At the end of the second month of the hospitalization period, the patient underwent a cranial MRI and abscess formation was detected diffusely with contrast enhancement (Figure 1c and 1d). We performed large frontotemporoparietal craniotomy allowing access to the interhemispheric fissure, abscess drainage, and removal of the solid, thickened walls of the abscesses by sharp dissection without disturbing the cohesiveness of the pia and the abscesses' walls in the second step (Figure $3 \mathrm{~b}$ and $3 \mathrm{~d}$ ). The patient had no neurologic sequel in the postoperative period; no abscess formation was detected and previous radiological findings of sinusitis and empyema were seen to have disappeared in the postoperative first year CT scans (Figure $4 \mathrm{a}$ and $4 \mathrm{~b}$ ) and MRI (Figure $4 \mathrm{c}$ and $4 d$ ).

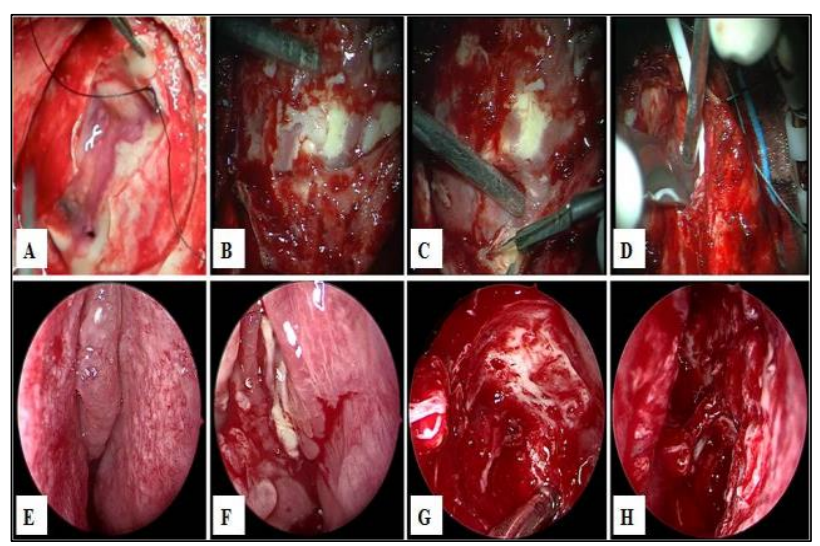

Figure 3a, 3b, 3c, 3d, 3e, 3f, 3g and 3h: Abscess formation in the subdural region during the first operation (a). Intraoperative views of second surgery including sharp dissection and heterogenous content of infective material (b, c, d). Preoperative endoscopic view of the left nasal cavity (e). Empyema in the middle meatus of the left side coming from the frontal sinus (f). Peroperative endoscopic view of the left nasal cavity (g). Postoperative endoscopic view of the left nasal cavity showing total removal of the disease with an adequate drainage pathway of the frontal sinus (h).

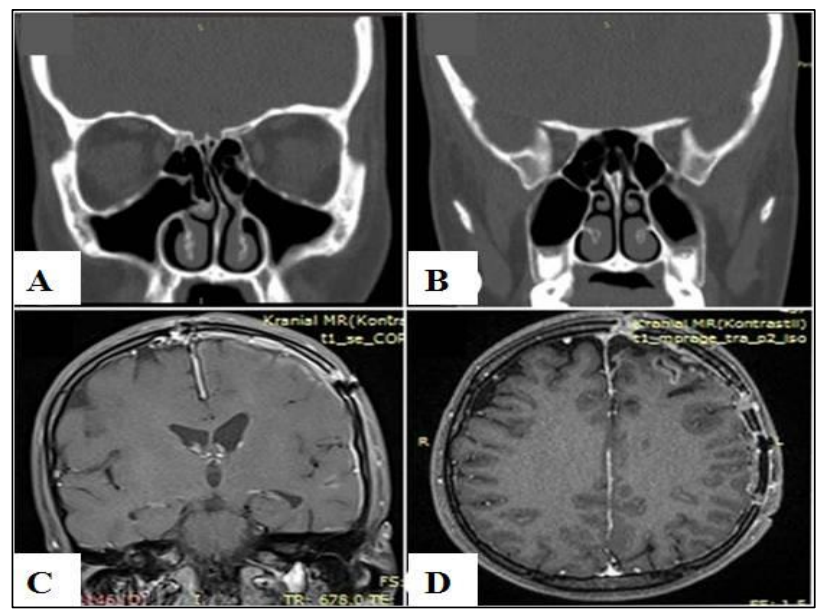

Figure 4a, 4b, 4c and 4d: Postoperative coronal sections of paranasal CT images showing no opacity in paranasal sinuses suspecting sinusitis $(\mathbf{a}, \mathbf{b})$. No abscess formation in the first year follow up cranial MRI (c, d).

\section{DISCUSSION}

Meningitis, thrombophlebitis of the venous sinus, cavernous sinus thrombosis and epidural, subdural and 
brain abscess complications may develop in children with acute sinusitis. ${ }^{4}$ Intracranial complications of sinusitis have been reported to range from $3.7 \%$ to $47.6 \%$ of cases. $^{5,6}$ Subdural empyema is the most common intracranial complication of sinusitis and is a rapidly developing neurosurgical emergency with surgical indication that leads to increased intracranial pressure and can cause coma and death within 24 to 48 hours if left untreated. , $^{2,3}$

The development of intracranial complications with sinusitis can be caused by direct extension or retrograde thrombophlebitis resulting from capless diploe veins. Retrograde thrombophlebitis originates from associated venous drainage of the paranasal sinuses and intracranial structures. The infection reaches subdural distance by passing through the cavernous and other dural sinuses because these are uncapped venous structures. ${ }^{2}$ Bone structure destruction was not noticed in the preoperative paranasal sinus CT or during the intraoperative period, so we assumed that the pathophysiology of the empyema was retrograde thrombophlebitis.

Radiological imaging should be performed in patients with suspected cranial complications. Although MRI shows parenchymal abnormalities that are superior to those from CT. ${ }^{8} \mathrm{CT}$ is preferred because of the need for rapid and broad diagnosis. ${ }^{2}$ Subdural empyema is viewed as a hypodense lesion on $\mathrm{CT}$ and evaluation of a midline shift and the bone structure of the paranasal sinuses is also important by CT but in the early cases of subdural empyema CT may not show fluid collection. ${ }^{9}$ These appear as a hypointense mass lesion in the T1 MRI sequence and a hyperintense lesion in the T2 sequence. ${ }^{8}$

The most common complaints from subdural empyema patients are headaches and fever and the most common clinical finding is neck stiffness. Confusion, cranial nerve palsies, hemiparesis, papilledema and septic shock are other signs that can be detected. ${ }^{2}$ Seizures are common in intracranial complications at a rate of $25-80 \%$ and are more common in subdural empyema. ${ }^{2}$ Singh et al evaluated 219 patients with sinusitis who developed intracranial complications. Of these, 22 patients had meningitis, 127 had subdural empyema, 38 had a brain abscess, 15 had both intracranial and extracranial abscesses and 17 had an extracranial abscess. The most common complaints were fever $(68 \%)$ and headache (54\%). The mortality rate was $16 \%$, and meningitis was the most common group of patients $(45 \%)$, followed by brain abscess (19\%) and subdural empyema $(11 \%){ }^{10}$

Sinus infections do not appear until late childhood because of sinus development and pneumatization after birth. ${ }^{11}$ Subdural empyema often occurs in healthy people in the second decade of life. ${ }^{12}$ Giannoni et al reviewed infected sinus origins in $12 \%$ of cranial abscess (43 cases) and $63 \%$ of extracranial abscess (16 cases); the average age was 12.2 years. ${ }^{11}$ In a study by Skelton et al, 7 of 10 patients had subdural empyema, 2 of 10 were extradural empyema and one patient had both complications with sinusitis. ${ }^{13}$ The first approach in the treatment of all patients was followed up with antibiotics; no improvement was detected with antibiotic treatment. Empyema drainage was performed on all patients, and sinus surgery was performed on three patients. One patient suffered from hydrocephalus, two patients presented with intractable epilepsy, seven patients had no sequelae or exitus. Two patients presenting with hemiparesis were resolved within 12 weeks. ${ }^{12}$ According to the literature review $12-37.5 \%$ had seizures, $15-35 \%$ had hemiparesis detected as subdural empyema morbidity, and approximately half of the cases had residual neurologic deficits. ${ }^{14-16}$

Sinogenic brain abscess often develops in the frontal lobes. ${ }^{17}$ Tall et al reported three of four subdural empyemas that they studied were located in the frontal lobe and others were located in temporoparietal areas, which they considered a complication of sinusitis cases. They performed simultaneous sinus surgery and intracranial empyema drainage for all patients and two patients had visual field loss. ${ }^{17}$ Boto et al performed decompressive craniectomy on untreated patients with maxillary and ethmoid sinusitis who developed intracranial hypertension and frontal cerebritis; hemiparesis and aphasia sequelae were observed in patients during the postoperative period. ${ }^{18}$ Kawano et al reported a patient with a stiff neck, aphasia, and hemiparesis following sinusitis; they detected an interhemispheric subdural empyema and performed sinus surgery and empyema drainage. ${ }^{19}$ Lang et al suggested empyema drainage with craniotomy and sinus surgery in 10 patients who developed subdural empyema following frontal sinusitis. ${ }^{20}$ Sinus surgery and abscess drainage are suggested for subdural empyemas occurring as a complication of sinusitis. ${ }^{17,19-25} \mathrm{We}$ performed abscess drainage with craniotomy and sinus surgery in emergency conditions as the first step. Temporoparietal craniotomy was performed because of frontal lobe tissue sensitivity. A more extensive craniotomy was planned after abscess formation, at which time we performed the second operation.

\section{CONCLUSION}

In conclusion subdural empyema, which results in high morbidity and mortality, is an uncommon but urgent neurosurgical condition. Urgent radiological imaging should be performed on patients who develop neurologic symptoms. Urgent abscess drainage with craniotomy and sinus surgery should be performed as the first step and the second step of abscess drainage should be performed after completion of abscess formation.

\section{ACKNOWLEDGMENTS}

Authors would like to acknowledge Turkish Neurosurgical Society for supporting in preparation of this article for publication. 
Funding: No funding sources

Conflict of interest: None declared

Ethical approval: Not required

\section{REFERENCES}

1. Nathoo N, Nadvi SS, van Dellen JR, Gouws E. Intracranial subdural empyemas in the era of computed tomography: A review of 699 cases. Neurosurg. 1999;44:529-35.

2. Osborn MK, Steinberg JP. Subdural empyema and other suppurative complications of paranasal sinuses. Lancet Infect Dis. 2007;7(1):62-7.

3. Kombogiorgas D, Seth R, Athwal R, Modha J, Singh J. Suppurative intracranial complications of sinusitis in adolescence. Single institute experience and review of literature. Brit $\mathrm{J}$ Neurosurg. 2007;21(6):603-9.

4. Bayram N, Vardar F, Yurtseven T, Eğrilmez S, Callı C. Preseptal cellulitis and subdural empyema cases as frontal sinusitis complication. J Pediatr Infect. 2010;4(2):79-81.

5. Younis RT, Lazar RH, Anand VK. Intracranial complications of sinusitis: A 15-year review of 39 cases. Ear Nose Throat J. 2002;81:636-8.

6. Clayman GL, Adams GL, Paugh DR, Koopmann $\mathrm{CF}$ Jr. Intracranial complications of paranasal sinusitis: A combined institutional review. Laryngoscope. 1991;101:234-9.

7. Waseem M, Khan S, Bomann S. Subdural empyema complicating sinusitis. J Emerg Med. 2008;35(3):277-81.

8. Younis RT, Anand VK, Davidson B. The role of computed tomography and magnetic resonance imaging in patients with sinusitis with complications. Laryngoscope. 2002;112:224-9.

9. Tsai YD, Chang WN, Shen CC, Lu CH, Liliang PC, $\mathrm{Su} \mathrm{TM}$, et al. Intracranial suppuration: a clinical comparison of subdural empyemas and epidural abscesses. Surg Neurol. 2003;59:191-6.

10. Singh B, Van Dellen J, Ramjettan S, Maharaj TJ. Sinogenic intracranial complications. J Laryngol Otol. 1995;109(10):945-50.

11. Giannoni C, Sulek M, Friedman EM. Intracranial complications of sinusitis: A pediatric series. Am J Rhinol. 1998;12(3):173-8.

12. Kaufman DM, Miller MH, Steigbigel NH. Subdural empyema: analysis of 17 recent cases and review of the literature. Med. 1975;54:485-98.

13. Skelton R, Maixner W, Isaacs D. Sinusitis-induced subdural empyema. Arch Dis Childhood. 1992;67:1478-80.

14. Hoyt DJ, Fisher SR. Otolaryngologic management of patients with subdural empyema. Laryngoscope. 1991;101:20-4.
15. Nathoo N, Nadvi SS, van Dellen JR, Gouws E. Intracranial subdural empyemas in the era of computed tomography: A review of 699 cases. Neurosurg. 1999;44:529-35.

16. Dill SR, Cobbs CG, McDonald CK. Subdural empyema: Analysis of 32 cases and review. Clin Infect Dis. 1995;20:372-86.

17. Tall A, Ba MC, Beketi A, Sy A, Loum B, Thiam $\mathrm{AB}$, et al. Subdural empyema complicating acute frontal sinusitis. Four cases report. Rev Laryngol Otol Rhinol (Bord). 2005;126(2):121-6.

18. Boto LR, Calado C, Vieira M, Camilo C, Abecasis F, Campos AR, et al. Subdural empyema due to gemella morbillorum as a complication of acute sinusitis. Acta Med Port. 2011;24(3):475-80.

19. Kawano H, Yonemura K, Misumi Y, Hashimoto Y, Hirano T, Uchino M. A case of interhemispheric subdural empyema with sinusitis diagnosed by diffusion-weighted MRI. Rinsho Shinkeigaku. 2005;45(6):449-52.

20. Lang EE, Curran AJ, Patil N, Walsh RM, Rawluk D, Walsh MA. Intracranial complications of acute frontal sinusitis. Clin Otolaryngol Allied Sci. 2001;26(6):452-7.

21. Belentani FM, Maia MS, Correa JP, Boccalini MCC, Sampaio AAL, Fávero ML. Subdural empyema-acute rhinosinusitis complication. Intl Arch Otorhinolaryngol. 2008;12(1):122-5.

22. Vaidyanathan V, Shetty K. Intracranial and orbital complications of dinusitis: a case series and review of literature. Clinical Rhinology: An Int J. 2011;4(2):87-92.

23. Clayman GL, Adams GL, Paugh DR, Koopmann CF Jr. Intracranial complications of paranasal sinusitis: a combined institutional review. Laryngoscope. 1991;101:234-9.

24. Wackym PA, Canalis RF, Feurman T. Subdural empyema otorhinolaryngol origin. J Laryngol Otol. 1990;104:118-22.

25. Martines F, Salvago P, Ferrara S, Mucia M, Gambino A, Sireci F. Parietal subdural empyema as complication of acute odontogenic sinusitis: A case report. J Med Case Reports. 2014;8:282.

Cite this article as: Yakar F, Dogan I, Ozgura O, Eroglu U, Beton S, Unlu A. Subdural empyema as a rare complication of sinonasal infection: a case report and review of literature. Int Surg J 2017;4:3519-22. 